\title{
MEDIA KOMIK SEBAGAI SARANA MENINGKATKAN KEMAMPUAN MENULIS
}

\author{
Silvia Sandi Wisuda Lubis \\ UIN Ar-Raniry, FTK, Prodi PGMI, Banda Aceh \\ silviasandi.lubis@ar-raniry.ac.id
}

\begin{abstract}
Abstrak. Media komik sudah sangat umum ditemukan dalam keseharian, tetapi penggunaan dalam meningkatkan kemampuan menulis perlulah dilakukan sebuah kajian atau pengamatan kembali. Penelitian ini menggunakan metode penelitian deskriptif kualitatif yang mana dasar pemikiran digunakannya metode ini adalah karena penelitian ini ingin mengetahui tentang fenomena yang ada dan dalam kondisi yang alamiah, bukan dalam kondisi terkendali, labolatoris atau eksperimen. Media komik memiliki kekhasan tersendiri yaitu dengan dipadukannya gambar untuk memberikan tambahan atau keterangan dalam menjelaskan isi cerita. Hal ini membuat kegiatan menulis menjadi lebih menyenangkan karena sudah dibantu dengan adanya tambahan gambar didalamnya. Penggunaan gambar dalam komik bisa digunakan sebagai membantu untuk mengembangkan imajinasi dalam menghasilkan sebuah tulisan. Hal ini juga dibuktikan dalam data yang ditemukan bahwa kemampuan siswa menulis karangan mengalami peningkatan dari siklus I hanya 17 siswa $(53,12 \%)$ yang tuntas dan pada siklus II meningkat menjadi 27 siswa $(84,37 \%)$ tuntas.
\end{abstract}

\section{Kata kunci : Komik, Menulis}

\begin{abstract}
Comic media is very common in day life, but its use in improving writing skills requires a study or re-observation. This study uses a qualitative descriptive research method in which the rationale for using this method is because this research wants to know about existing phenomena and in natural conditions, not in controlled, metabolic or experimental conditions. Comic media has its own uniqueness, namely the combination of images to provide additional or information in explaining the content of the story. This makes writing more enjoyable because it has been helped by the addition of pictures in it. The use of images in comics can be used to help develop imagination in producing writing. This is also proven in the data found that the ability of students to write essays has increased from the first cycle only 17 students (53.12\%) completed and in the second cycle increased to 27 students $(84.37 \%)$ completed.
\end{abstract}

Keywords: Comic, Writing 


\section{Silvia Sandi Wisuda Lubis MEDIA KOMIK SEBAGAI SARANA MENINGKATKAN KEMAMPUAN MENULIS}

\section{PENDAHULUAN}

Kegiatan menulis masih dianggap menjadi sebuah kegiatan yang membutuhkan upaya keras karena memerlukan imajinasi, diksi yang tepat, olah rasa di dalamnya agar menghasilkan sebuah tulisan yang indah dan menarik untuk dibaca. Tidak sedikit pula yang beranggapan kegiatan menulis merupakan kegiatan yang membosankan karena menguras pikiran dan dilakukan dalam sitausi yang monoton yaitu hanya memindahkan sesuatu yang ada dalam pikiran ke dalam bentuk tulisan. Sebenarnya kegiatan yang menarik, membosankan, menyenangkan, atau memusingkan ? Sebenarnya jawabannya dikembalikan kepada individu masingmasing. Kesenangan, minat setiap orang berbeda-beda atau bisa dikatakan relatif. Kebahagiaan atau kesenangan dalam diri seseorang hanyalah orang itu sendiri yang dapat mennetukan dan mengukurnya. Namun, kebanyakan kegiatan menulis tidaklah sebuah menjadi hobi atau kesenangan anak muda saat ini. Anak muda saat ini dengan perkembangan teknologi yang ada cenderung memanfaatkan penggunaan youtube, media sosial untuk mengembangkan atau menumpahkan imajinasinya yang sebenarnya hakikat dasarnya sama dengan menulis. Konon lagi, anak atau siswa yang sama sekali tidak memiliki ketertarikan dalam menulis. Jika tidak diimbau untuk menulis, siswa atau anak tidak akan melakukan kegiatan menulis. Kegiatan menulis bagi siswa hanya sebatas ketika sedang mengerjakan soal atau tugas bahasa Indonesia yang biasanya sering meminta siswa untuk menulis sebuah karangan bebas, puisi, pantun. Kegiatan menulis bisa berupa menulis novel, cerita pendek, artikel, opini,komik, dan lainnya.
Media komik berbeda dengan media lainnya karena di dalamnya terdapat gambar yang mendukung isi cerita. Maka dari itu, kegiatan menulis komik membutuhkan kemampuan menggambar di dalamnya. Kemampuan menggambar yang tidak hanya sekadar bisa menggambar melainkan kemampuan menggambar yang profesional agar menghasilkan sebuah komik yang baik. Semua komik hanya mengacu pada cerita humoris untuk menghibur. Komik merupakan peninggalan zaman masa lampau pada masyarakat yang belum mengenal tulisan, komik yang menjadi cerita adalah pada ilustrasi atau gambar itu sendiri. Ilustrasi ini bisa dilengkapi dengan narasi atau tidak. Ilustrasi dalam komik harus mempunyai sebuah runtutan yang berbentuk cerita.

Komik adalah salah satu media hiburan yang sering digunakan dalam kehidupan sehari-hari, mungkin tak pernah disadari bahwa masa kecil seseorang tidak terlepas dari media visual ini. Melalui komik kita dapat belajar banyak hal, yaitu belajar membaca, memahami isi bacaan, atau cerita dengan cara visual dengan mengenal warna dan suatu bentuk bacaan.

Komik juga dapat digunakan sebagai media pembelajaran dalam dunia pendidikan karena komik dapat dirancang sesuai dengan materi yang akan disampaikan. Dalam hal ini komik berfungsi sebagai penyampaian pesan pembelajaran dengan media visual yang dikemas semenarik mungkin agar siswa lebih tertarik untuk belajar. Media visual ini memegang peranan penting dalam proses belajar karena dapat merangsang proses pemahaman dan memperkuat 


\section{Silvia Sandi Wisuda Lubis MEDIA KOMIK SEBAGAI SARANA MENINGKATKAN KEMAMPUAN MENULIS}

ingatan siswa. ${ }^{1}$ Bukan hanya itu, komik juga dapat menumbuhkan minat siswa untuk belajar serta memberikan hubungan antara isi materi pembelajaran dengan dunia nyata. Sehingga muncul efek yang membekas pada siswa yang dapat mengingat sesuatu yang lebih lama. ${ }^{2}$ Media komik tidak hanya dapat meningkatkan motivasi siswa untuk membaca, akan tetapi keterampilan menulis juga dapat ditingkatkan. Dengan adanya gambar-gambar yang menarik dapat membantu siswa dalam menyalurkan ide dan gagasannya dalam tulisan.

\section{METODE PENELITIAN}

\section{Penelitian ini menggunakan metode kualitatif deskriptif. Menurut Sugiono, penelitian kualitatif adalah penelitian dimana peneliti ditempatkan sebagai instrument kunci, teknik pengumpulan data dilakukan secara penggabungan dan analisis data bersifat induktif. $^{3} \quad$ Menurut Poerwandari, penelitian kualitatif menghasilkan dan mengolah data yang sifatnya deskriptif, seperti observasi. ${ }^{4}$ Kirk dan Miller (dalam Moleong) mendefinisikan penelitian}

\footnotetext{
${ }^{1}$ Azhar Arsyad, Media Pembelajaran,

(Jakarta: Rajawali Pers, 1996), h. 91.

${ }^{2}$ Azhar Arsyad, Media..., h. 91.

${ }^{3}$ Sugiyono, Metode Penelitian Pendidikan Pendekatan Kualitatif, Kuantitatif, dan R\&D. (Bandung : Alfabeta, 2010), h. 9

${ }^{4}$ Poerwandari, E.K, Pendekatan Kualitatif untuk Penelitian Perilaku Manusia, (Depok: LPSP3 Fakultas Psikologi Universitas Indonesia), h. 19
}

kualitatif sebagai cara untuk melakukan pengamatan langsung pada individu dan berhubungan dengan orang-orang tersebut untuk mendapatkan data yang digalinya. ${ }^{5}$

Dasar pemikiran digunakannya metode ini adalah karena penelitian ini ingin mengetahui tentang fenomena yang ada dan dalam kondisi yang alamiah, bukan dalam kondisi terkendali, labolatoris atau eksperimen. Di samping itu, karena peneliti perlu untuk langsung terjun ke lapangan bersama objek penelitian sehingga jenis penelitian kualitatif deskripstif kiranya lebih tepat untuk digunakan.

Sesuai dengan permasalahan yang menjadi fokus dalam penelitian ini yaitu gambaran deskriptif mengenai penggunaan media komik sebagai sarana untuk meningkatkan kemampuan menulis, maka peneliti menggunakan pendekatan kualitatif dengan mendeskripsikan data yang peneliti peroleh sebagai hasil suatu penelitian. Dengan menggunakan metode ini, maka peneliti akan mendapatkan data secara utuh dan dapat dideskripsikan dengan jelas sehingga hasil penelitian ini benar-benar sesuai dengan kondisi lapangan yang ada. Adapun yang menjadi subyek penelitian adalah tingkat siswa sekolah dasar atau MI.

\footnotetext{
${ }^{5}$ Moleong, Lexy, J. Metodologi Penelitian

Kualitatif, (Bandung : Remaja Rosdakarya), h. 3
} 


\section{Silvia Sandi Wisuda Lubis \\ MEDIA KOMIK SEBAGAI SARANA MENINGKATKAN KEMAMPUAN MENULIS}

\section{PEMBAHASAN}

1. Pengertian Menulis

Menulis merupakan suatu kegiatan komunikasi berupa penyampaian pesan (informasi) secara tertulis (oleh penulis) kepada pihak lain (pembaca) dengan menggunakan bahasa tulis sebagai alat atau medianya. Menulis itu sendiri adalah sebagai suatu keterampilan berbahasa yang komplek. Menulis terdapat pada kemampuan penulis menyusun dan mengorganisasikan isi tulisannya serta menuangkan dalam bentuk tulisan ragam bahasa tulis. Di balik kerumitannya, menulis banyak mengandung manfaat bagi pengembangan mental, intelektual, dan sosial seseorang.

Pengajaran menulis, baik ysng dimulsi pada tingkat sekolah dasar atau di sekolah tingkat MI ataupun yang lebih tinggi pada hakikatnya merupakan pengajaran yang aktif produktif, yaitu menghasilkan (menghasilkan pesan), yang hasilnya nanti berupa tulisan. Pengajaran menulis ini dapat meningkatkan pengembangan kecerdasan seseorang dalam berbagai aspek, mengembangkan daya inisiatif dan kreativitas, serta menumbuhkan keberanian dan mendorong kemauan dan kemampuan mengumpulkan informasi.

Menulis merupakan sebuah proses kreatif menuangkan gagasan dalam bentuk bahasa tulis dalam tujuan memberi tahu, meyakinkan atau menghibur. Hasil dari kreatif ini bisa disebut dengan istilah karangan atau tulisan. Karangan adalah bentuk tulisan yang mengungkapkan pikiran dan perasaan pengarang satu kesatuan tema yang utuh. Karangan diartikan pula dengan rangkaian hasil pemikiran atau ungkapan perasaan pengarang ke dalam bentuk tulisan yang utuh dan teratur. ${ }^{6}$ Kemampuan mengarang tidak lain dari kemampuan melahirkan pikiran, perasaan dan pengalaman dengan bahasa yang baik. Berdasarkan beberapa pendapat para ahli di atas dapat

${ }^{6}$ Kosasih, Ketatabahasaan dan disimpulkan bahwa menulis adalah proses penyampaian pikiran, anganangan dan perasaan dalam bentuk lambang/tanda/tulisan yang bermakna. Kegiatan menulis dapat pengembangan kecerdasan siswa dalam berbagai aspek, mengembangkan daya inisiatif, kreativitas, serta menumbuhkan keberanian, mendorong kemauan, dan kemampuan mengumpulkan informasi.

2. Fungsi Pembelajaran Menulis

a. Aspek Penting Dalam Menulis Aspek penting dalam menulis adalah kemampuan seseorang dalam mengapresiasikan pikiran, perasaan dan gagasan melalui bahasa tulis dengan tepat. Aspek-aspek dalam menulis karangan adalah sebagai berikut: ${ }^{7}$

1) Penentuan Pikiran Utama

Salah satu ciri utama tulisan yang baik adalah adanya bahasa kesatuan gagasan antar paragrafnya. Sebuah tulisan (karangan) akan menjadi jelas jika mempunyai kesatuan, yaitu semua detil yang berupa contoh, ataupun fakta yang digunakan tidak boleh menyimpang dari pikiran utama.

Seperti dikemukakan oleh Mukhsin Ahmadi "pikiran utama adalah pengendali suatu karangan sehingga dengan pemikiran utama dimasukkan isi karangan tidak akan menyimpang". Karangan tersebut ditulis dalam bentuk paragraf dan tiap paragraf mempunyai pemikiran utama. Pemikiran utama yang paling baik diletakkan pada kalimat pertama pada paragraf.

2) Pembentukan paragraf

Agar sebuah karangan mudah ditangkap pembaca dan jelas, maka perlulah disusun suatu paragraf. Paragraf merupakan suatu pikiran atau perasaan yang tersusun teratur berupa kaliamat-kalimat dan berfungsi sebagai bagian dari suatu bagian yang lebih besar.

3) Penulisan kalimat

\section{${ }^{7}$ Akhadiah Maidar, Pembinaan}

Kemampuan Menulis Bahasa Indonesia...,h.

12. 


\section{Silvia Sandi Wisuda Lubis \\ MEDIA KOMIK SEBAGAI SARANA MENINGKATKAN KEMAMPUAN \\ MENULIS}

Kalimat dalam karangan harus jelas dan mudah dipahami, karena kalimat tertulis dalam beberapa hal tidak sama dengan kalimat tutur. Kalimat yang jelas dan terang dalam bahasa percakapan (tutur) tidak selamanya jelas dan terang, juga apabila dituliskan, sebab intonasi dalam bahasa tutur sulit untuk diterjemahkan dalam bahasa tulis.

Jadi, aspek penting dalam menulis terdiri dari tiga yaitu: penentuan pikiran utama, pembentukan paragraf, dan penulisan kalimat. Setiap menulis ketiga aspek tersebut harus ada. Penentuan pikiran utama adalah pengendali suatu karangan sehingga dengan memperhatikan pikiran utama karangan akan menjadi jelas dan terarah. Sedangkan paragraf dibutuhkan untuk memudahkan pembaca menangkap isi karangan dengan jelas, sedangkan pengunaan kalimat yang jelas dan mudah dipahami dalam karangan sangat menentukan kualitas sebuah karangan.

\section{Langkah-langkah Menulis}

$$
\text { Menurut Tompkins yang }
$$

dikutip oleh Ahmad Susanto menguraikan proses menulis menjadi lima tahap yang meliputi: ${ }^{8}$

a. Tahap Pra-menulis

Tahap ini merupakan tahap siap menulis atau tahap penemuan menulis. Pada tahap pra-menulis siswa berusa mengemukakan apa yang mereka tulis.

b. Tahap Penyusunan Draf Tulisan

Dalam proses menulis, siswa menulis dan menyaring tulisan mereka melalui sejumlah konsep. Selama tahap penyusunan konsep siswa terfokus dalam pengumpulan gagasan.

c. Tahap perbaikan

Dalam tahap ini, siswa menyaring ide-ide dalam tulisan mereka.

d. Tahap Penyuntingan

${ }^{8}$ Ahmad Susanto, Teori Belajar dan Pembelajaran di sekolah Dasar, (Jakarta: Kencana Prenada Media Group, 2013), h. 247.
Pada tahap ini, siswa menyempurnakan tulisan mereka dengan mengkoreksi ejaan. Tujuan agar membuat tulisan menjadi siap baca secara optimal.

e. Tahap Publikasi

Pada tahap akhir ini, siswa sudah siap membacakan hasil tulisannya melalui kegiatan penugasan siswa untuk membaca siswa karangan didepan kelas.

\section{Media Komik}

a. Pengertian Media Komik

Komik berasal dari bahasa Perancis, "comique" dan dari bahasa Yunani "komikos" yang berarti lucu atau menggelitik. Semua komik hanya mengacu pada cerita humoris atau satiris untuk menghibur para pembaca yang ada di dalam cerita komik (lucu). Dalam perkembangannya komik berarti menjelaskan semua

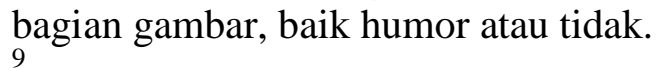

Komik adalah sebuah kartun yang mengungkapkan suatu karakter dan menerangkan suatu cerita dalam urutan yang erat, dihubungkan dengan gambar dan dirancang untuk memberikan hiburan kepada para pembaca. Derry Mayendra mengemukakan "komik adalah bagian dari budaya popular karena sebelumnya proses pembelajaran hanya menggunakan buku biasa. Spiderman dan Batman adalah film yang diambil dari komik yang dapat berpengaruh terhadap keberhasilan dalam proses belajar". ${ }^{10}$ Anak persekolahan, yang disukai adalah komik dengan tokoh hewan, misalnya Mickey Mouse, Donal Bebek dan Doraemon, yang berpakaian dan berbicara seperti manusia. Akan tetapi, sebenarnya anak persekolahan menyukai semua komik dengan syarat tidak mengandung unsur teror. ${ }^{11}$

${ }^{9}$ Masnur Muslich , Melaksanakan PTK itu Mudah, (Jakarta: Bumi Aksara, 2010), h. 140.

${ }^{10}$ Derry Mayendra, Budaya Populer,

(Jakarta: Universitas Gunadarma, 2011), h. 1.

$$
{ }^{11} \text { Derry Mayendra, Budaya }
$$

Populer..., h. 2. 


\section{Silvia Sandi Wisuda Lubis \\ MEDIA KOMIK SEBAGAI SARANA MENINGKATKAN KEMAMPUAN \\ MENULIS}

Komik sebagai media merupakan salah satu media yang dipandang efektif untuk membelajarkan dan mengembangkan kreativitas berpikir. Media komik adalah sebagai bentuk rangkaian gambar masing-masing dalam kotak yang seluruhnya merupakan rentetan suatu cerita. Gambar-gambar itu dilengkapi balon-balon, ada juga masih disertai narasi sebagai penjelas.

\section{b. Ciri-Ciri Komik}

Komik memiliki beberapa ciri-ciri tersendiri sehingga dapat membedakannya dengan karya sastra yang lain, yaitu sebagai berikut: ${ }^{12}$

1) Menggambarkan cerita lewat ilustrasi (gambar)

2) Komik memiliki kata-kata lebih sedikit

3) Komik menggunakan bahasa percakapan didalam cerita

4) Komik tersusun gambar rangkaian seri yang saling berkaitan

5) Komik memiliki warna gambar

6) Komik juga bisa tidak memiliki warna gambar

7) Gambar komik dengan cerita saling berkaitan

8) Komik hadir untuk menyampaikan materi pembelajaran lewat media komik.

\section{HASIL PEMBAHASAN}

1. Kemampuan

Menulis

Karangan

Setelah kegiatan pembelajaran pada siklus I berlangsung, diberikan soal post test untuk mengetahui kemampuan siswa menulis karangan setelah menerapkan media komik hasil post test siklus I dapat dilihat pada tabel berikut ini:

Tabel I. Hasil Post Test Siklus I

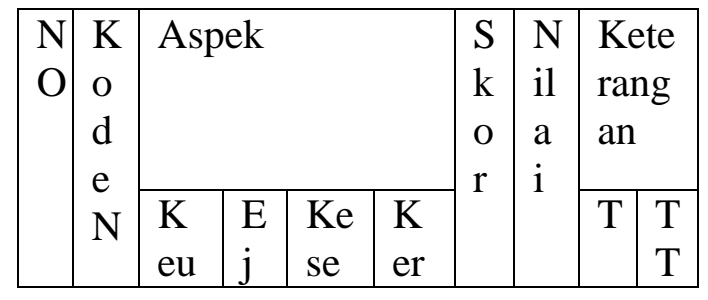

${ }^{12}$ Mc S. Cloud, Membuat Komik,

(Jakarta: Gramedia, 2008), h. 9.

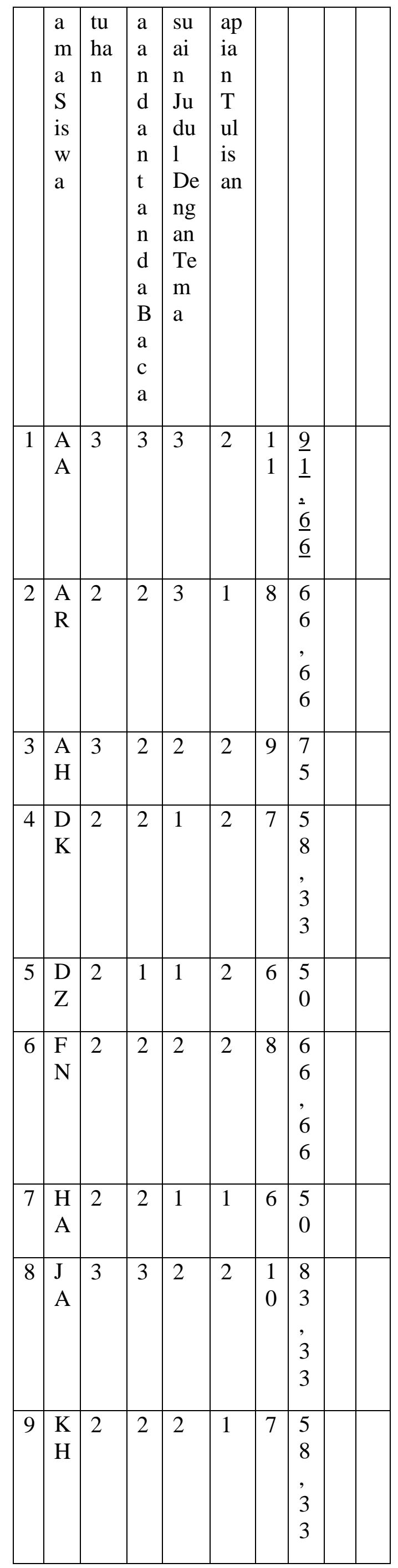


Silvia Sandi Wisuda Lubis

MEDIA KOMIK SEBAGAI SARANA MENINGKATKAN KEMAMPUAN

MENULIS

\begin{tabular}{|c|c|c|c|c|c|c|c|}
\hline $\begin{array}{l}1 \\
0\end{array}$ & $\begin{array}{l}\mathrm{K} \\
\mathrm{N}\end{array}$ & 3 & 2 & 2 & 2 & 9 & $\begin{array}{l}7 \\
5\end{array}$ \\
\hline $\begin{array}{l}1 \\
1\end{array}$ & $\begin{array}{l}\mathrm{K} \\
\mathrm{F}\end{array}$ & 3 & 3 & 2 & 1 & 9 & $\begin{array}{l}7 \\
5\end{array}$ \\
\hline $\begin{array}{l}1 \\
2\end{array}$ & $\begin{array}{l}\mathrm{L} \\
\mathrm{N}\end{array}$ & 2 & 3 & 1 & 2 & 8 & $\begin{array}{l}6 \\
6 \\
6 \\
6 \\
6\end{array}$ \\
\hline $\begin{array}{l}1 \\
3\end{array}$ & $\begin{array}{l}\mathrm{M} \\
\mathrm{F}\end{array}$ & 3 & 3 & 3 & 1 & $\begin{array}{l}1 \\
0\end{array}$ & $\begin{array}{l}8 \\
3 \\
3 \\
3\end{array}$ \\
\hline $\begin{array}{l}1 \\
4\end{array}$ & $\begin{array}{l}\mathrm{M} \\
\mathrm{I}\end{array}$ & 2 & 1 & 2 & 3 & 8 & $\begin{array}{l}6 \\
6 \\
6 \\
6\end{array}$ \\
\hline $\begin{array}{l}1 \\
5\end{array}$ & $\begin{array}{l}\mathrm{M} \\
\mathrm{M}\end{array}$ & 3 & 3 & 1 & 2 & 9 & $\begin{array}{l}7 \\
5\end{array}$ \\
\hline $\begin{array}{l}1 \\
6\end{array}$ & $\begin{array}{l}\mathrm{M} \\
\mathrm{A}\end{array}$ & 2 & 1 & 3 & 1 & 7 & $\begin{array}{l}5 \\
8 \\
3 \\
3\end{array}$ \\
\hline $\begin{array}{l}1 \\
7\end{array}$ & $\begin{array}{l}\mathrm{M} \\
\mathrm{L}\end{array}$ & 3 & 3 & 3 & 2 & $\begin{array}{l}1 \\
1\end{array}$ & $\begin{array}{l}9 \\
1 \\
6 \\
6 \\
6\end{array}$ \\
\hline $\begin{array}{l}1 \\
8\end{array}$ & $\begin{array}{l}\mathrm{M} \\
\mathrm{D}\end{array}$ & 2 & 1 & 1 & 2 & 6 & $\begin{array}{l}5 \\
8 \\
3 \\
3\end{array}$ \\
\hline $\begin{array}{l}1 \\
9\end{array}$ & $\begin{array}{l}\mathrm{M} \\
\mathrm{U}\end{array}$ & 3 & 2 & 2 & 2 & 9 & $\begin{array}{l}7 \\
5\end{array}$ \\
\hline $\begin{array}{l}2 \\
0\end{array}$ & $\begin{array}{l}\mathrm{M} \\
\mathrm{Z}\end{array}$ & 3 & 2 & 2 & 2 & 9 & $\begin{array}{l}7 \\
5\end{array}$ \\
\hline $\begin{array}{l}2 \\
1\end{array}$ & $\begin{array}{l}\mathrm{N} \\
\mathrm{M}\end{array}$ & 2 & 3 & 2 & 2 & 9 & $\begin{array}{l}7 \\
5\end{array}$ \\
\hline $\begin{array}{l}2 \\
2\end{array}$ & $\begin{array}{l}\mathrm{N} \\
\mathrm{A}\end{array}$ & 3 & 2 & 2 & 3 & $\begin{array}{l}1 \\
0\end{array}$ & $\begin{array}{l}8 \\
3 \\
3 \\
3\end{array}$ \\
\hline $\begin{array}{l}2 \\
3\end{array}$ & $\begin{array}{l}\mathrm{N} \\
\mathrm{P}\end{array}$ & 3 & 2 & 2 & 2 & 9 & $\begin{array}{l}7 \\
5\end{array}$ \\
\hline
\end{tabular}

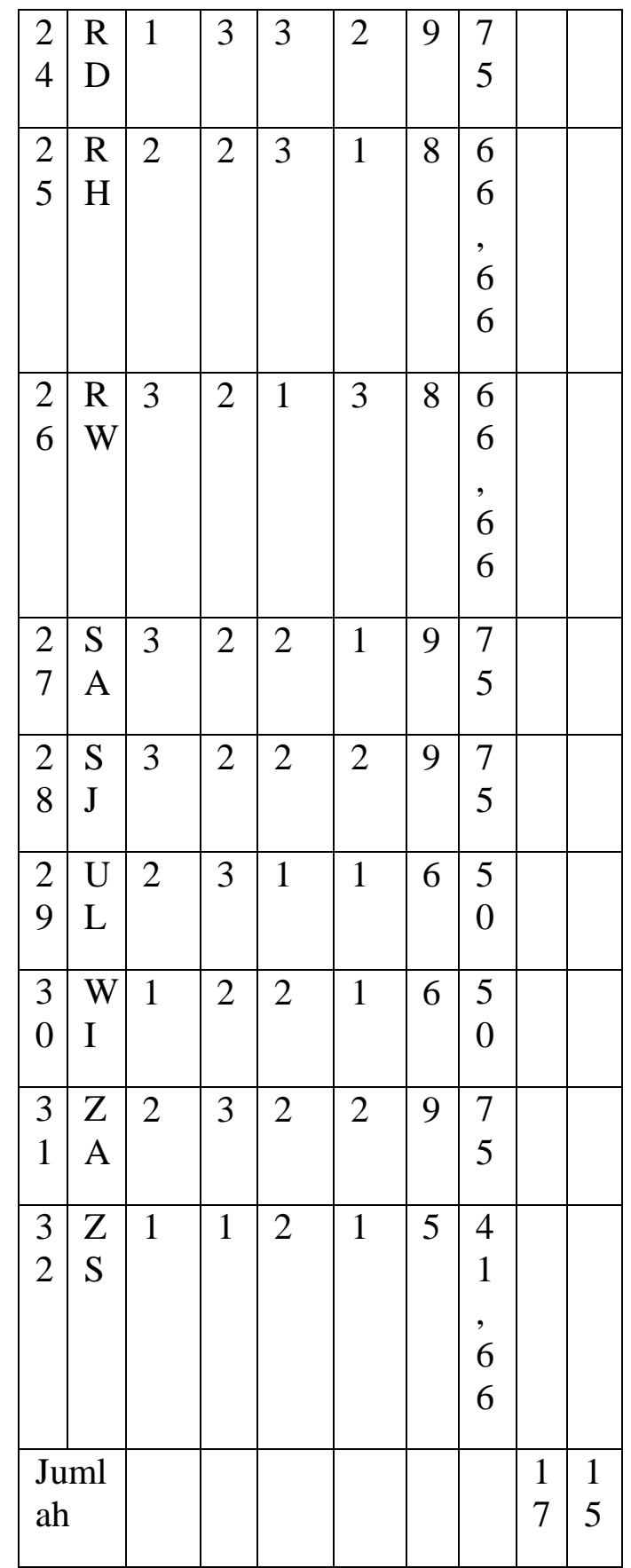

Sumber: Hasil penelitian di MIN 3 Aceh Besar Juli 2020

Ketuntasan Klasikal $=\underline{\text { Jumlah siswa }}$ yang tuntas $x 100 \%$ Jumah total siswa

$=\underline{17} \times 100 \%=53,12 \%$

Berdasarkan tabel diatas bahwa terlihat sebanyak 17 orang siswa yang tuntas dengan persentase 53,12 sedangkan siswa yang tidak tuntas adalah sebanyak 15 siswa dengan persentase $46,87 \%$. Sehingga dapat disimpulkan pada pembelajaran siklus I belum tuntas. Sehingga dapat disimpulkan bahwa hasil belajar siswa pada siklus I belum tuntas karena belum mencapai nilai KKM yang ditetapkan yaitu 70 untuk individu dan 75 secara klasikal artinya hasil belajar siswa dianggap tuntas jika perolehan nilai Bahasa Indonesia 
Silvia Sandi Wisuda Lubis

MEDIA KOMIK SEBAGAI SARANA MENINGKATKAN KEMAMPUAN

MENULIS

minimal 70 secara individu dan 75 secara klasikal.

Setelah kegiatan pembelajaran pada siklus II berlangsung, diberikan soal post test untuk mengetahui kemampuan siswa menulis karangan setelah menerapkan media komik, hasil post test siklus II dapat dilihat pada tabel berikut ini:

Tabel II. Hasil Post Test Siklus II

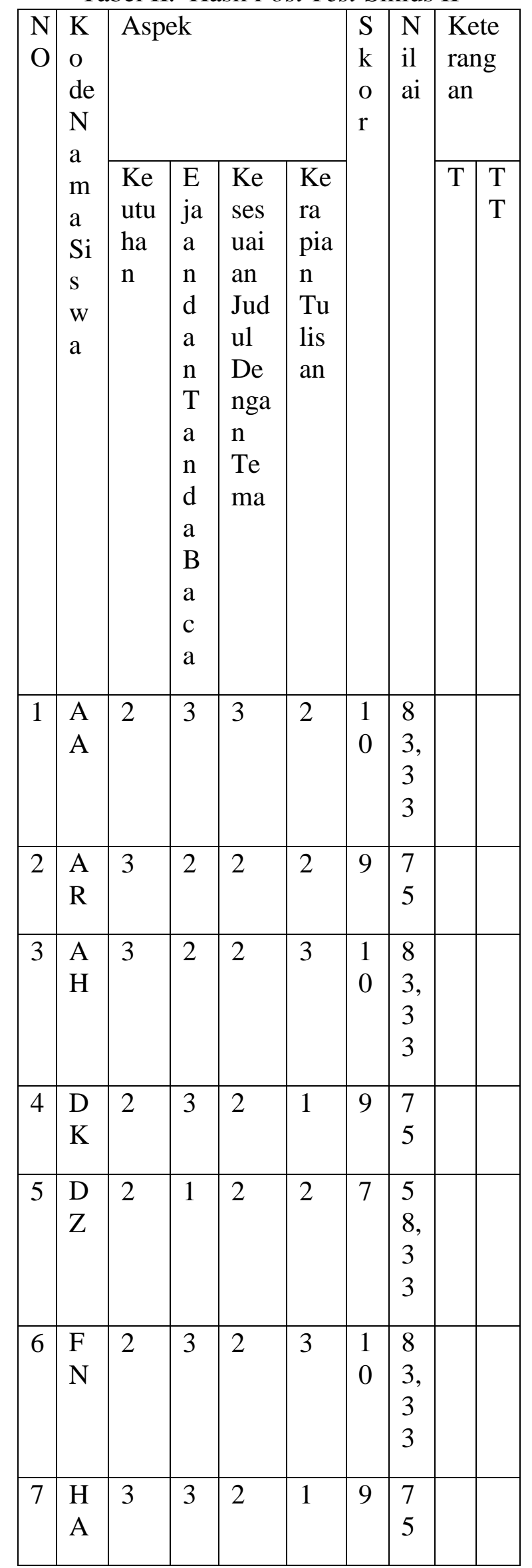

\begin{tabular}{|c|c|c|c|c|c|c|c|}
\hline 8 & $\begin{array}{l}\mathrm{J} \\
\mathrm{A}\end{array}$ & 2 & 3 & 3 & 2 & $\begin{array}{l}1 \\
0\end{array}$ & $\begin{array}{l}8 \\
3, \\
3 \\
3\end{array}$ \\
\hline 9 & $\begin{array}{l}\mathrm{K} \\
\mathrm{H}\end{array}$ & 2 & 2 & 3 & 1 & 8 & $\begin{array}{l}6 \\
6, \\
6 \\
6\end{array}$ \\
\hline 0 & $\begin{array}{l}\mathrm{K} \\
\mathrm{N}\end{array}$ & 3 & 3 & 2 & 2 & $\begin{array}{l}1 \\
0\end{array}$ & $\begin{array}{l}8 \\
3, \\
3 \\
3\end{array}$ \\
\hline 1 & $\begin{array}{l}\mathrm{K} \\
\mathrm{F}\end{array}$ & 2 & 1 & 3 & 3 & 9 & $\begin{array}{l}7 \\
5\end{array}$ \\
\hline 1 & $\begin{array}{l}\mathrm{L} \\
\mathrm{N}\end{array}$ & 1 & 3 & 3 & 2 & 9 & $\begin{array}{l}7 \\
5\end{array}$ \\
\hline 1 & $\begin{array}{l}\mathrm{M} \\
\mathrm{F}\end{array}$ & 3 & 2 & 2 & 1 & 9 & $\begin{array}{l}7 \\
5\end{array}$ \\
\hline $\begin{array}{l}1 \\
5\end{array}$ & $\begin{array}{l}\mathrm{M} \\
\mathrm{M}\end{array}$ & 3 & 1 & 3 & 3 & $\begin{array}{l}1 \\
0\end{array}$ & $\begin{array}{l}8 \\
3, \\
3 \\
3\end{array}$ \\
\hline 6 & $\begin{array}{l}\mathrm{M} \\
\mathrm{A}\end{array}$ & 1 & 1 & 3 & 1 & 6 & $\begin{array}{l}5 \\
0\end{array}$ \\
\hline $\begin{array}{l}1 \\
7\end{array}$ & $\begin{array}{l}\text { M } \\
\text { L }\end{array}$ & 3 & 3 & 2 & 2 & $\begin{array}{l}1 \\
0\end{array}$ & $\begin{array}{l}8 \\
3, \\
3 \\
3\end{array}$ \\
\hline $\begin{array}{l}1 \\
8\end{array}$ & $\begin{array}{l}\mathrm{M} \\
\mathrm{D}\end{array}$ & 2 & 2 & 2 & 3 & 9 & $\begin{array}{l}7 \\
5\end{array}$ \\
\hline $\begin{array}{l}1 \\
9\end{array}$ & $\begin{array}{l}\mathrm{M} \\
\mathrm{U}\end{array}$ & 3 & 3 & 2 & 2 & $\begin{array}{l}1 \\
0\end{array}$ & $\begin{array}{l}8 \\
3, \\
3 \\
3\end{array}$ \\
\hline 0 & $\begin{array}{l}\mathrm{M} \\
\mathrm{L}\end{array}$ & 2 & 1 & 2 & 1 & 6 & $\begin{array}{l}5 \\
0\end{array}$ \\
\hline $\begin{array}{l}2 \\
1\end{array}$ & $\begin{array}{l}\mathrm{N} \\
\mathrm{M}\end{array}$ & 3 & 3 & 2 & 3 & $\begin{array}{l}1 \\
1\end{array}$ & $\begin{array}{l}9 \\
1, \\
6 \\
6\end{array}$ \\
\hline $\begin{array}{l}2 \\
2\end{array}$ & $\begin{array}{l}\mathrm{N} \\
\mathrm{A}\end{array}$ & 3 & 2 & 2 & 3 & $\begin{array}{l}1 \\
0\end{array}$ & $\begin{array}{l}8 \\
3, \\
3 \\
3\end{array}$ \\
\hline $\begin{array}{l}2 \\
3\end{array}$ & $\begin{array}{l}\mathrm{N} \\
\mathrm{P}\end{array}$ & 2 & 2 & 3 & 3 & $\begin{array}{l}1 \\
0\end{array}$ & $\begin{array}{l}8 \\
3, \\
3 \\
3\end{array}$ \\
\hline
\end{tabular}




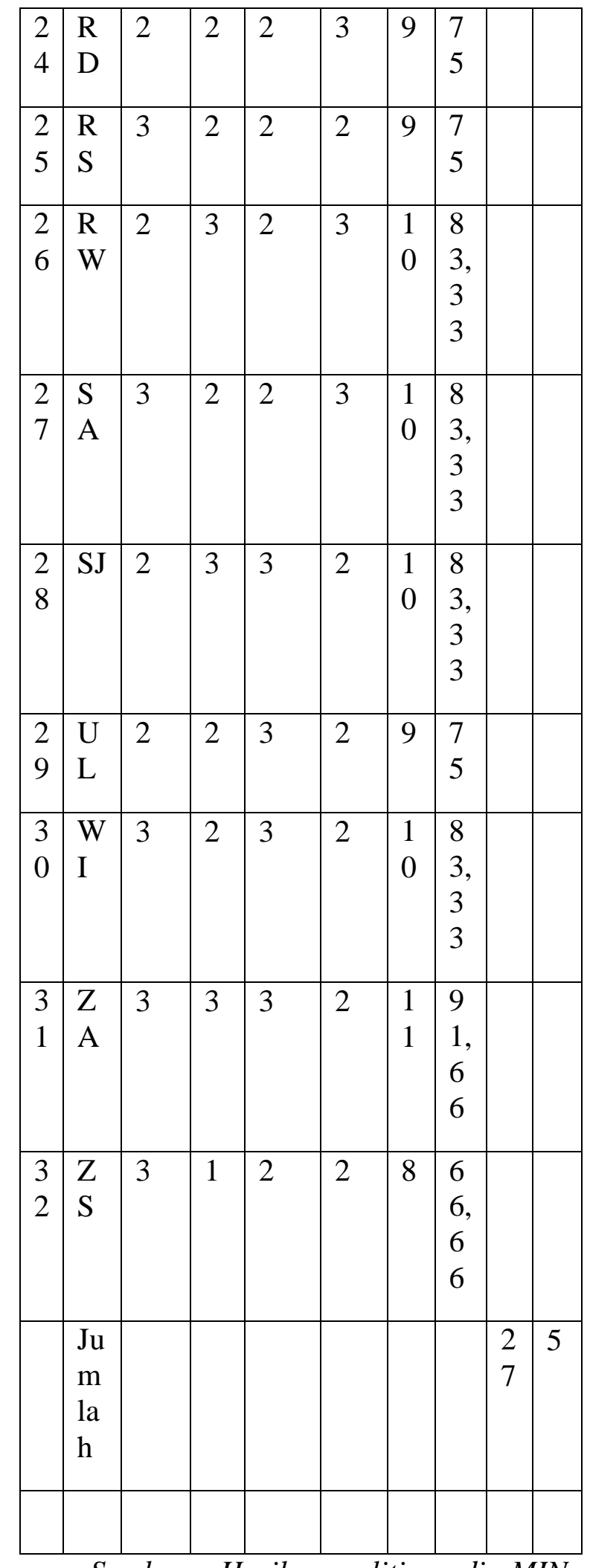

Sumber: Hasil penelitian di MIN 3Aceh Besar Juli 2020

Ketuntasan Klasikal = Jumlah Siswa yang tuntas $\times 100 \%$

\section{Jumlah total siswa$$
=\underline{27} \times 100 \%=84,37 \%
$$

Berdasarkan tabel di atas dapat diketahui bahwa 27 orang siswa $(84,37 \%)$ tuntas dan 5 orang siswa $(15,62)$ belum tuntas. Hal ini menunjukkan bahwa kemampuan menulis karangan siswa di siklus II meningkat dibandingkan dengan siklus I.

\section{SIMPULAN}

Media komik memiliki kekhasan tersendiri yaitu dengan dipadukannya gambar untuk memberikan tambahan atau keterangan dalam menjelaskan isi cerita. Hal ini membuat kegiatan menulis menjadi lebih menyenangkan karena sudah dibantu dengan adanya tambahan gambar didalamnya. Penggunaan gambar dalam komik bisa digunakan sebagai membantu untuk mengembangkan imajinasi dalam menghasilkan sebuah tulisan. Hal ini juga dibuktikan dalam data yang ditemukan bahwa kemampuan siswa menulis karangan mengalami peningkatan dari siklus I hanya 17 siswa $(53,12 \%)$ yang tuntas dan pada siklus II meningkat menjadi 27 siswa $(84,37 \%)$ tuntas.

\section{SARAN}

Berdasarkan simpulan di atas, maka saran dari penelitian ini adalah:

1. Media komik sudah mulai harus digalakkan oleh guru agar siswa memiliki alternatif untuk membantu mengembangkan imajinasi dalam menulis.

2. Dukungan dari sekolah untuk memberikan pelatihan menulis bagi guru agar guru juga memiliki keterampilan menulis yang baik.

3. Galakkan kegiatan perlombaan menulis bagi siswa untuk memberikan peluang sekaligus tantangan kepada siswa dalam menghasilkan sebuah tulisan.

\section{DAFTAR PUSTAKA}

Azhar Arsyad. 1996. Media Pembelajaran. Jakarta: Rajawali Pers.

Cloud Mc S. 2008. Membuat Komik. Jakarta: Gramedia.

Masnur $\quad 2010$. Melaksanakan PTK itu Mudah. Jakarta: Bumi Aksara. Ahmad Susanto. 2013 Teori Belajar dan Pembelajaran di sekolah Dasar. Jakarta: Kencana Prenada Media Group. 
Maidar Akhadiah. 2008. Pembinaan Kemampuan Menulis Bahasa Indonesia. Jakarta:Erlangga.

Kosasih. 2003. Ketatabahasaan dan Kesastraan. Bandung: Yrama Widya.

Mayendra Derry. 20011. Budaya Populer. Jakarta: Universitas Gunadarma.

Sugiyono. 2010. Metode Penelitian Pendidikan Pendekatan Kualitatif, Kuantitatif, dan $R \& D$. Bandung : Alfabeta

Poerwandari, E.K. 2005. Pendekatan Kualitatif untuk Penelitian Perilaku Manusia. Depok: LPSP3 Fakultas Psikologi Universitas Indonesia

Moleong, Lexy, J. 2012. Metodologi Penelitian Kualitatif. Bandung : Remaja Rosdakarya 